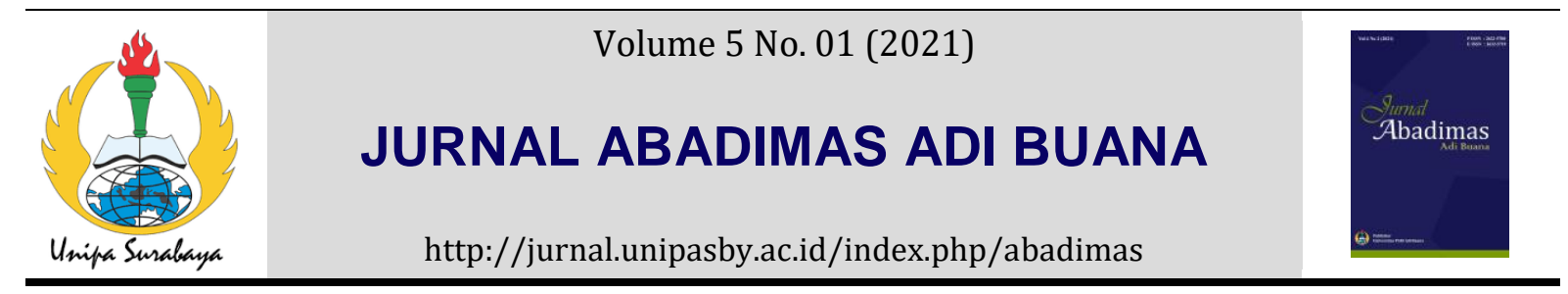

\title{
LITERASI KEUANGAN BAGI KELUARGA DI MASA PANDEMIC COVID 19
}

\author{
Maria Assumpta Evi Marlina ${ }^{1}$ dan Anastasia Filiana Ismawati ${ }^{2 *}$ \\ ${ }^{1}$ Program Studi Akuntansi, Universitas Ciputra, Surabaya, Indonesia \\ Email : anastasia.filiana@ciputra.ac.id
}

\begin{abstract}
Informasi Artikel Abstrak
Kata kunci:

Pengelolaan keuangan

dasar, pengelolaan

hutang, pandemi

COVID 19

Diterima: 11-12-2021

Disetujui: 24-06-2021

Dipubikasikan: 14-07-

2021

Kegiatan pengabdian kepada masyarakat yang diikuti oleh para peserta yaitu para orang tua siswa SMA Citra Berkat. Para peserta merupakan pihak yang merasakan dengan adanya pandemi COVID 19 berdampak pada keuangan keluarga. Kegiatan Program Literasi Keuangan Bagi Keluarga Di Masa Pandemi COVID 19 yang diselenggarakan oleh Pusat Layanan Akuntansi dan Perpajakan Program Studi Akuntansi Universitas Ciputra memiliki tujuan untuk membuka peluang dan wawasan atas literasi keuangan khususnya pada pengelolaan keuangan dasar dan pengelolaan hutang keluarga di masa pandemi COVID 19. Pelaksanaan program ini dilaksanakan dengan metode daring dan disertai dengan pemaparan materi dan diskusi dengan para pakar mengenai pengelolaan keuangan dasar keluarga dan pengelolaan hutang. Pemberian materi tersebut, maka para orang tua siswa dapat dilengkapi dengan berbagai informasi dan strategi pengelolana keuangan. Hasil dari pelaksanaan program ini adalah konsep dan pemahaman bagi para peserta mengenai literasi keuangan dasar keluarga dan pengelolaan hutang di keluarga mengalami peningkatan.
\end{abstract}

\section{Abstract}

Keywords :

Basic

management,

management,

19 pandemic
Community service activities participated in by the participants, namely the parents of Citra Berkat High School students. The participants are parties who feel that the COVID-19 pandemic has an impact on family finances.

financial debt Financial Literacy Program Activities for Families During the COVID-19

COVID Pandemic Period organized by the Center for Accounting and Taxation Services Accounting Study Program at Ciputra University has the aim of opening up opportunities and insights on financial literacy, especially in basic financial management and family debt management during the COVID 19 pandemic. This program is implemented using an online method and is accompanied by material presentations and discussions with experts on basic family financial management and debt management. By providing these materials, parents can be equipped with various information and financial management strategies. The result of the implementation of this program is a concept and understanding for the participants regarding basic family financial literacy and debt management in the family. 


\section{PENDAHULUAN}

Berawal dari kebutuhan akan pengelolaan keuangan keluarga di masa pandemi COVID 19 yang memberikan pengaruh bagi perekonomian. Melakukan swakarantina akibat pandemi COVID 19 tidak mudah dan berimbas ke banyak aspek termasuk perekonomian keluarga. Beberapa kasus yang menimpa dan berpengaruh pada ekonomi keluarga adalah pemecatan, pemotongan gaji, hutang yang tidak dapat dilunasi dan akses berjualan langsung ke konsumen yang dibatasi.

Pengelolaan keuangan keluarga memerlukan keterampilan dalam pengaturan dan manajemen yang baik dan cermat. Penghasilan yang kecilpun apabila dikelola dengan baik dapat memenuhi kewajiban dan kebutuhan utama keluarga. Namun, dalam pelaksanaannya, pengelolaan keuangan dalam keluarga harus disikapi dengan bijaksana dalam memilih kebutuhan dan menerapkan manajemen keuangan keluarga yang baik agar dapat mendatangkan kebahagiaan dan kesejahteraan keluarga. Pentingnya pemahaman mengenai literasi keuangan karena keputusan keuangan yang tepat dapat meningkatkan kesejahteraan masyarakat di masa depan (Setiawan, 2020)

SMA Citra Berkat sebagai sebuah institusi pendidikan yang berada di Surabaya dan didesain dengan pola belajar yang memfasilitasi siswa agar dapat mengelola 5 tahap kerja (Exploring, Planning, Doing, Communicating, Reflecting). Gambaran orang tua siswa dari SMA Citra Berkat adalah 53\% karyawan swasta, 27\% wiraswasta dan $20 \%$ sebagai ibu rumah tangga dengan kisaran usia 40 hingga 50 tahun keatas.

Permasalahan mitra diantaranya adalah kebutuhan untuk pengelolaan keuangan khususnya pengelolaan keuangan dasar dan pengelolaan hutang di masa pandemic COVID 19. Permasalahan tersebut diakibatkan dari adanya pemotongan gaji, pemutusan hubungan kerja, prioritas pengajuan hutang, kesulitan dalam berhubungan dengan calon konsumen serta kesulitan dalam memasarkan produk dan jasanya. Selain beberapa hal tersebut, pengelolaan hutang juga dibutuhkan karena pendapatan yang menurun berisiko menjadikan kredit macet.

Program pengelolaan keuangan keluarga ini akan berfokus pada pengelolaan keuangan yang termasuk prioritas pengeluaran, pos pemasukan keluarga dan juga pengelolaan utang yang mencakup mengenai evaluasi kebutuhan aktivitas keluarga yang akan didanai oleh utang. Diharapkan dengan adanya pengelolaan keuangan dan hutang yang baik, maka kondisi keluarga dapat lebih sejahtera.

Pemilihan prioritas dalam keuangan keluarga perlu ditetapkan dan dilaksanakan dalam keluarga. Guna mendukung hal tersebut, Layanan Akuntansi dan Perpajakan Program Studi Akuntansi Universitas Ciputra (PLAP ACC UC) menyelenggarakan kegiatan diskusi mengenai penerapan literasi keuangan pada keluarga bagi para orang tua siswa SMA Citra Berkat. Tujuan dari kegiatan tersebut berfokus pada pemberian wawasan bagi para orang tua siswa SMA Citra Berkat dalam penataan keuangan keluarga yang disesuaikan dengan kemampuan ekonomi keluarga. 


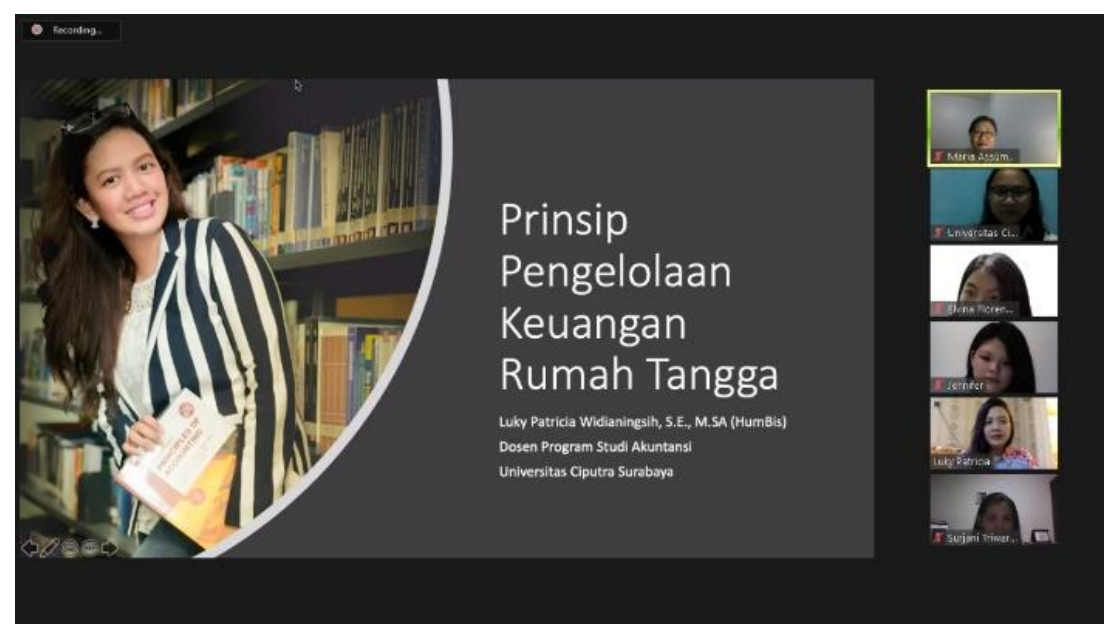

Gambar 1. Pelaksanaan pengabdian masyarakat melalui media daring

\section{METODE}

Mitra yang dipilih dalam pelaksanaan pengabdian kepada masyarakat adalah orang tua siswa SMA Citra Berkat. Hak ini karena terdapat beberapa orang tua siswa yang terkena dampak dari pandemi COVID 19 terutama di area Surabaya. Selama kegiatan pengabdian kepada masyarakat, para orang tua siswa SMA Citra Berkat diajak untuk meningkatkan semangat dan berdiskusi bersama dengan narasumber.

Metode pelaksanaan kegiatan pengelolaan keuangan keluarga diawali dengan perencanaan pelaksanaan acara. Tim pelaksana melakukan pemetaan kebutuhan para orangtua siswa SMA SCB yang ditelurusi melalui wawancara singkat dengan kepala sekolah SMA Citra Berkat dan Ketua Komite orang tua siswa. Pemetaan dilakukan dengan tujuan untuk memastikan bahwa materi yang disampaikan dapat sesuai dengan kebutuhan dan permasalahan para orangtua siswa SMA Citra Berkat dan dapat diaplikasikan dalam keluarga.

Berdasarkan pemetaan kebutuhan para orangtua siswa SMA Citra Berkat, pelaksanaan kegiatan diskusi mengenai pengelolaan keuangan keluarga dilaksanakan pada tanggal 16 Oktober 2020 melalui media daring. Pelaksana dan narasumber dalam kegitan tersebut adalah para Dosen Program Studi Akuntansi Universitas Ciputra dan 3 mahasiswa Program Studi Akuntansi Universitas Ciputra. Pemilihan narasumber yang memberikan pemaparan mengenai pengelolaan keuangan didasarkan pada pemetaan kebutuhan para orangtua siswa SMA Citra Berkat. 


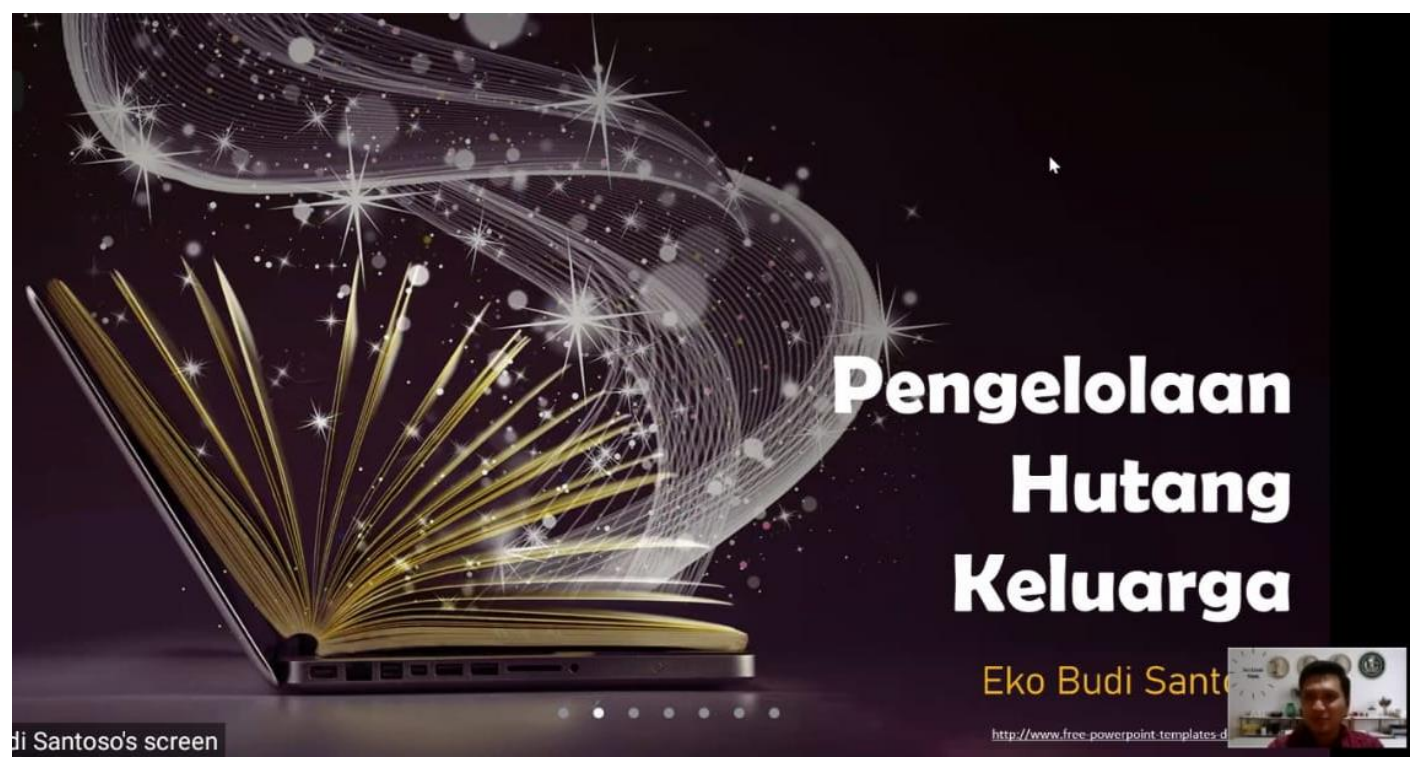

Gambar 2. Pemaparan Materi Mengenai Pengelolaan Hutang Keluarga

Pelaksanaan kegiatan diawali dengan pemaparan materi mengenai dasar pengelolaan keuangan keluarga dan pengelolaan hutang. Materi yang diberikan juga dibagikan kepada peserta untuke evaluasi lebih lanjut. Setelah pemaparan materi, para orang tua siswa SMA Citra Berkat dilibatkan dalam proses diskusi dan tanya jawab. Pelaksanaan kegiatan melalui metode daring dikarenakan pandemic covid 19. Pelaksanaan kegiatan juga akan melibatkan narasumber yang sesuai latar belakangnya. Pemaparan materi dan diskusi akan dilaksanakan guna membantu para peserta untuk lebih memahami tidak hanya konsep, namun hingga ke penerapannya.

Pada tahap terakhir yaitu evaluasi, ketua pelaksana, tim dan narasumber akan melakukan evaluasi atas kegiatan yang dilaksanakan. Kendala dan masalah teknis akan didiskusikan dan divaluasi agar tidak terulang pada kegiatan berikutnya.

\section{HASIL DAN PEMBAHASAN}

Pelaksanaan diskusi mengenai pengelolaan keuangan yang dilaksakan pada 16 Oktober 2020 dengan media daring dilaksanakan dengan metode diskusi antar narasumber dan para orang tua siswa SMA Citra Berkat. Proses diskusi didukung oleh para Dosen Program Studi Akuntansi Universitas Ciputra. Proses diskusi dilaksanakan dengan pemaparan materi oleh narasumber dengan materi prinsip pengelolaan keuangan keluarga dan pengelolaan hutang keluarga dan sesi diskusi diikuti oleh 20 peserta. Diskusi dengan didukung oleh 3 asisten dosen yang bertugas untuk melakukan rekap data dan dokumentasi.

Diskusi dilakukan dengan menggali permasalahan para orang tua murid SMA Citra Berkat dan diskusi ini dilakukan untuk mencapai hasil yang diharapkan yaitu pengelolaan keuangan yang efektif dan efisien di masa pandemic. Diskusi ini dilaksanakan dengan saling berbagi pengalaman dan 
diberikan masukan, sehingga para orang tua siswa SMA Citra Berkat langsung bisa merefleksikan dan menerapkan pengelolaan keuangan yang tepat berdasar dari hasil diskusi tersebut. Diharapkan dengan adanya proses diskusi dengan Bapak/Ibu Dosen yang kompeten di bidangnya dapat membantu para orang tua siswa SMA Citra Berkat dalam mengelola keuangan mereka, khususnya pada penggunaan dana dan pengelolaan prioritas dan pembayaran hutang.

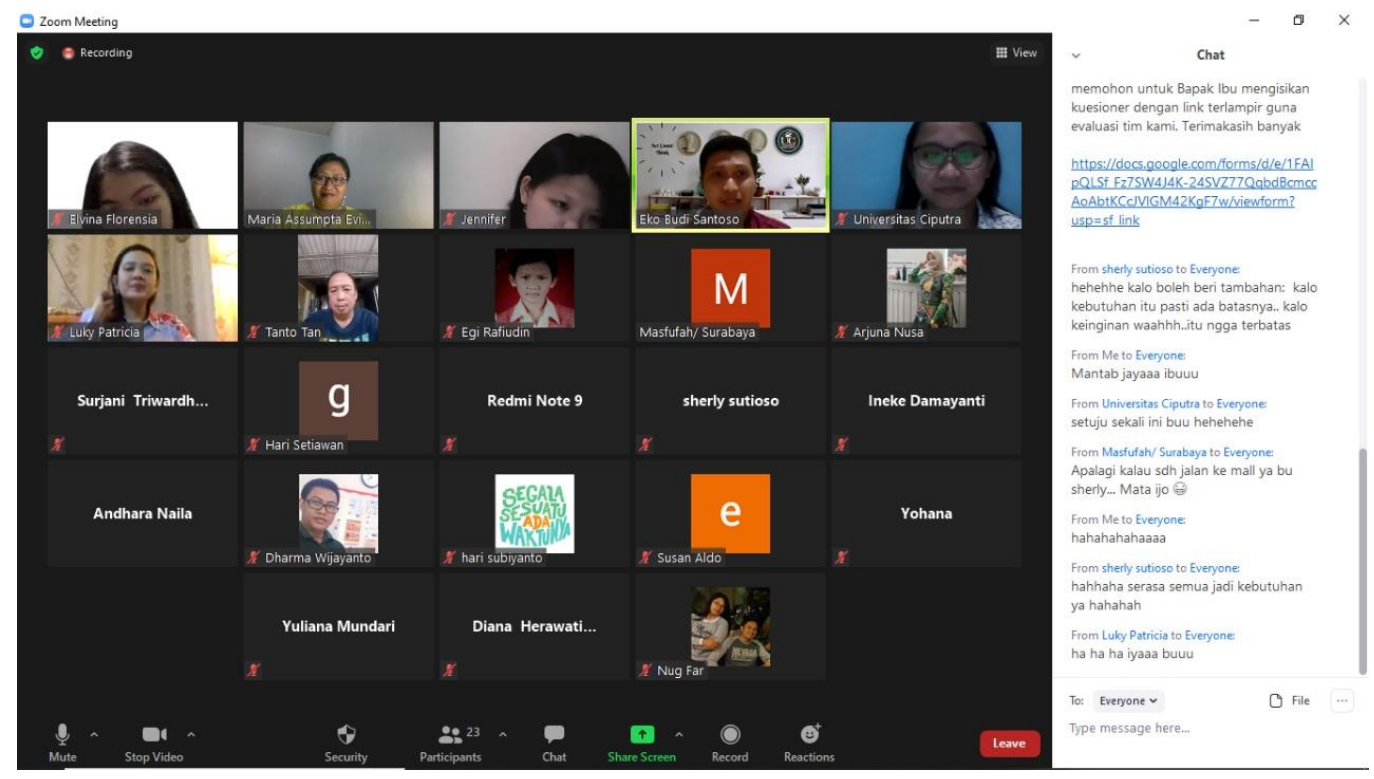

Gambar 3. Kegiatan diskusi pengelolaan keuangan keluarga

Hasil pelaksanaan kegiatan dievaluasi berdasarkan umpan balik dari para orangtua siswa SMA Citra Berkat yang memberikan respon bahwa diskusi ini sangat berguna dan membuka wawasan. Dibuktikan dengan hasil diskusi dengan Ibu Masfufah sebagai salah satu peserta yang paling aktif dalam diskusi ini dan memberikan umpan balik bahwa dengan adanya diskusi ini beliau dapat lebih paham dalam menerapkan prioritas keuangan keluarga. Pemaparan materi dan diskusi memberikan pemahaman bagi peserta baik konsep maupun penerapan. Para peserta dapat langsung melakukan interaksi dengan para narasumber. Pertanyaan dan diskusi yang dapat memeberikan pandangan baru dan pemecahan masalah dari para peserta.

Dampak dari kegiatan terhadap mitra adalah orang tua siswa SMA Citra Berkat dapat mengelola keuangan keluarga termasuk juga pengelolaan hutang sehingga perekonomian keluarga dapat optimal. Keahlian dan keterampilan yang dimiliki oleh para narasumber diharapkan dapat memberikan kontribusi dalam pemberian solusi dalam hal mengelola keuangan dan hutang khususnya di masa pandemi. Gambar 3 menunjukkan salah satu bentuk tanggapan dari peserta yang menunjukkan bahwa kebutuhan atas hutang tidak boleh didasari untuk lifestyle.

Selain itu, untuk menyebarluaskan informasi dan pentingnya pengelolaan keuangan keluarga didukung oleh timesindonesia.co.id. Diharapkan dengan adanya artikel tersebut dapat membantu 
seluruh keluarga yang perekonomiannya terdampak pandemi COVID 19 dapat menerapkan pengelolaan keuangan keluarga yang efektif dan efisien.

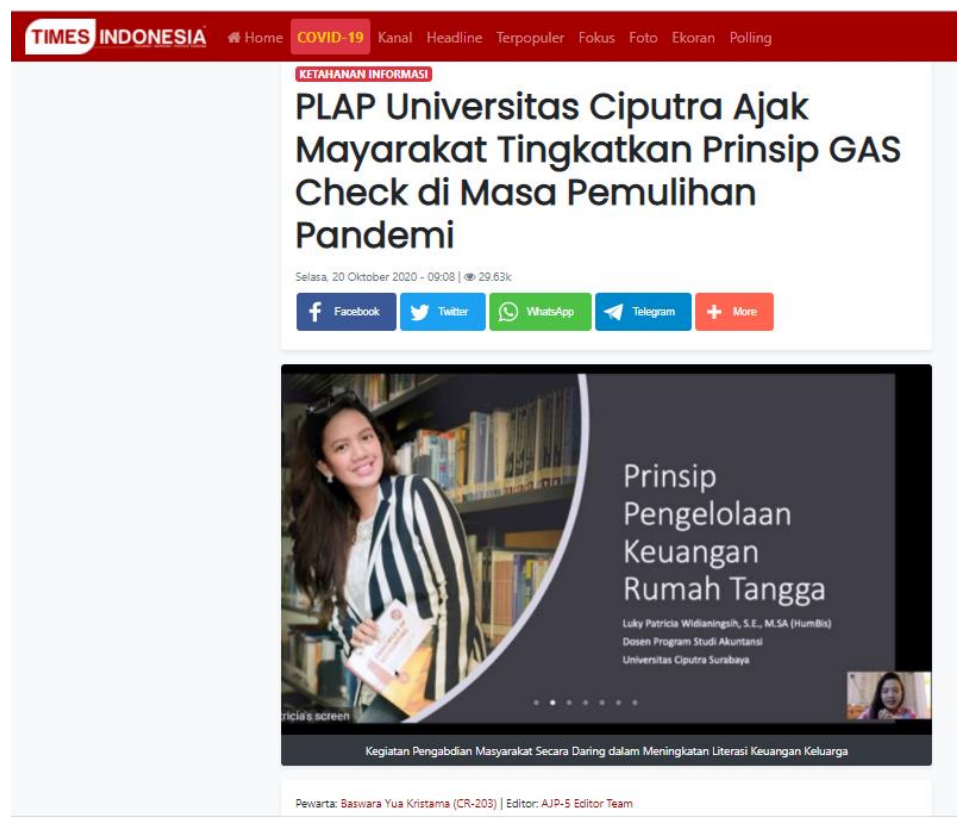

Gambar 4. Publikasi artikel pengabdian masyarakat di timesindonesia.co.id

\section{KESIMPULAN}

Program diskusi mengenai pengelolaan keuangan dan hutang bagi para orang tua siswa SMA Citra Berkat mendapatkan respon yang baik dari para peserta. Salah satu dampak dari kegiatan ini adalah peningkatan pengetahuan bagi para orang tua siswa SMA Citra Berkat dalam mengelola keuangan keluarga dan memprioitaskan dalam pemilihan hutang. Pentingnya pemahaman mengenai pengelolaan keuangan dan hutang dalam keluarga dapat memberikan wawasan untuk membuat ekonomi keluarga menjadi lebih optimal. Selain itu, pemilihan narasumber yang sesuai dengan kebutuhan, memiliki keterampilan dan pengetahuan terhadap proyek mempermudah peserta memperoleh wawasan

\section{UCAPAN TERIMAKASIH}

Pelaksana kegiatan pengabdian kepada masyarakat Program Studi Akuntansi Universitas Ciputra mengucapkan terima kasih kepada:

1. Lembaga Penelitian dan Pengabdian Masyarakat (LPPM) Universitas Ciputra atas dukungannya berupa pendaaan, hingga dapat terselenggara Kegiatan Program Konsultasi Bisnis dan Keuangan Bagi Pengusaha di Kota Baru, Driyorejo, Gresik, Jawa Timur, pada tanggal 24 April 2019. 
2. Ibu Surjani Triwardhani selaku Ketua Sekolah SMA Citra Berkat, Bapak Wibowo selaku Ketua komite orang tua siswa dan para orang tua siswa SMA Citra Berkat, atas kesediaannya menjadi mitra pengabdian masyarakat

3. Para Bapak/Ibu Dosen dan Mahasiswa di Program Studi Akuntansi Fakultas Manajemen dan Bisnis Universitas Ciputra atas dukungannya dalam mensukseskan kegiatan pengabdian masyarakat

4. Terima kasih juga disampaikan kepada media masa online timesindonesia.co.id, yang telah memberikan kesempatan untuk menyebarluaskan pelaksanaan kegiatan pengabdian masyarakat.

5. Terima kasih juga disampaikan kepada media masa online timesindonesia.co.id yang telah memberikan kesempatan untuk menyebarluaskan pelaksanaan kegiatan pengabdian masyarakat

\section{DAFTAR PUSTAKA}

Anugerah, M Fajar. et al. (2020). Sosialisasi Tata kelola Penanganan COVID dan Tindakan Preventif di Era New Normal. Bernas:Jurnal Pengabdian Kepada Masyarakat. 1(4). 441-448

Damayanti, Fitri. et al. (2017). Pengabdian Kepada Masyarakat Untuk Siwa dan Pengelola Pusat Kegiatan Belajar Masyarakat Di Kabupaten Bangkalan. Jurnal Pengabdian Dan Penerapan IPTEK. 1(1). 47-54.

Khoiriah, Neneng. et al. (2020). Memperkenalkan Manajemen Keuangan dengan Skala Prioritas Keuangan Pada Ibu-Ibu Rumah Tangga Kelurahan Pondok Benda. Jurnal Pengabdian Dharma Laksana Mengabdi Untuk Negeri. 2(1). 73-78.

Masduki. et al. (2020). Sosialisasi dan Edukasi Pengelolaan Keuangan Bagi Pelaku Usaha Mikro Kecil dan Menengah Desa Gandu Kecamatan Dawuan. Bernas:Jurnal Pengabdian Kepada Masyarakat. 1(4). 583-588.

Mulyani, Hani Sri. et al. (2020). Kemandirian Desa Melawan Covid-19 Secara Ekonomi Berbasis Potensi Desa. Bernas:Jurnal Pengabdian Kepada Masyarakat. 1(4). 481-490.

Mulyanti, Dwinta \& Nurdin, Sahidillah. (2018). Pelatihan Perencanaan Keuangan Keluarga Bagi Ibu Ibu PKK Desa Cimenyan Kabupaten Bandung. Jurnal ABDIMAS BSI. 1(2). 259-267.

Persulessy, Grace. et al. (2019). Pengelolaan Keuangan Keluarga dalam rangka peningkatan literasi keuangan. Jurnal pengabdian dan pemberdayaan masyarakat. 1(1). 90-96.

Rushadiyati. et al. (2017). Penyuluhan Tentang Manajemen Keuangan Keluarga di RW 06 Kelurahan Cipayung Jakarta Timur. Jurnal Pelayanan dan Pengabdian Masyarakat. 1(1). 49-59.

Setiawan, Budi. (2020). Literasi Keuangan Pelaku Usaha Mikro, Kecil Dan Menengah (Umkm) Kota Palembang. Jurnal Abdimas Mandiri. 4(2). 70-75.

Sukirman. et al. (2019). Pengelolaan Keuangan Keluarga dalam Rangka Peningkatan Masyarakat Mandiri dan Berperan dalam Peningkatan Literasi Keuangan Indonesia (Otoritas Jasa Keuangan). Jurnal Pengabdian Kepada Masyarakat UNNES. 23(2). 165-169.

Surahman, Arif. et al. (2020). Menumbuhkan Motivasi Bekerja dan Cara Mengatur Keuangan Selama Masa PSBB COVID 19. Jurnal Abdi Masyarakat. 1(2). 136-141. 